\title{
PENGARUH FAKTOR KEBUTUHAN EKONOMI TERHADAP DINAMIKA RUANG RUMAH INDUSTRI KUE PIA WARUREJO PASURUAN
}

\author{
Benny Karunia Wardana \\ Mahasiswa Program Magister Jurusan Arsitektur Lingkungan Binaan (ALB) \\ Fakultas Teknik, Universitas Brawijaya, Malang \\ e-mail: bennyarchitecture@gmail.com \\ Lisa Dwi Wulandari \\ Dosen Program Magister Jurusan Arsitektur Lingkungan Binaan (ALB) \\ Fakultas Teknik, Universitas Brawijaya, Malang \\ e-mail: lisaromansya@ub.ac.id \\ Agung Murti Nugroho \\ Dosen Program Magister Jurusan Arsitektur Lingkungan Binaan (ALB) \\ Fakultas Teknik, Universitas Brawijaya, Malang \\ e-mail: agungmurti@ub.ac.id
}

\begin{abstract}
ABSTRAK
Era globalisasi yang semakin berkembang pesat, tingkat pertumbuhan dalam perekonomian yang terus meningkat tidak sebanding dengan jumlah pekerjaan yang didapat. Penduduk menengah kebawah akan kesulitan dalam mencari pekerjaan. Untuk itu para penduduk menengah ke bawah membangun sebuah industri di dalam rumahnya untuk menyambung kehidupan. Rumah industri merupakan sebuah rumah yang berbeda dari rumah pada umumnya karena pada rumah industri memiliki dua fungsi yakni sebagai tempat tinggal dan sebagai area industri.

Penelitian ini merupakan jenis penelitian deskriptif kualitatif. Teori yang digunakan adalah teori milik Hermanto, 2008 terkait ruang yang terfokus pada aspek bentuk ruang dan ukuran ruang. Metode yang digunakan dalam penelitian ini adalah metode fenomenologi. Tahapannya adalah menganalisis bentuk ruang (perubahan ruang dan fungsi ruang)dan ukuran ruang dengan menggunakan analisis deskriptif (antar studi terpilih) dan analisis komparatif (kajian jurnal terdahulu). Tujuan penelitian ini untuk mengetahui sejauh mana perkembangan dinamika ruang yang terjadi pada rumah industri yang dipengaruhi oleh faktor ekonomi. Hasilnya adalah ada 3 jenis faktor ekonomi yang ada disana yakni, faktor ekonomi biasa, faktor ekonomi menengah dan faktor ekonomi tinggi. Faktor ekonomi biasa mempengaruhi sedikit ruang, faktor ekonomi menengah mempengaruhi sebagian beberapa ruang (setengah) dalam rumah sedangkan faktor ekonomi yang tinggi mempengaruhi semua pola ruang di dalam rumah.
\end{abstract}

Kata kunci : kebutuhan ekonomi, rumah industri kue pia, dinamika ruang

Jurnal PAWON Jurnal PAWON, Nomor 03 Volume III, Juli-Desember 2019, ISSN 2597-7636 


\begin{abstract}
The era of globalization is growing rapidly, the rate of growth in the economy that continues to increase is not proportional to the number of jobs obtained. Middle and lower residents will find it difficult to find work. For this reason, the lower middle class residents build an industry in their homes to connect their lives. An industrial house is a house that is different from a house in general because the industrial house has two functions, namely as a residence and as an industrial area.

This research is a type of qualitative descriptive research. The theory used is the theory of Hermanto, 2008 related to space focused on aspects of the shape of space and the size of space. The method used in this study is the phenomenology method. The stages are analyzing the shape of space (changes in space and function of space) and the size of space using descriptive analysis (between selected studies) and comparative analysis (review of previous journals). The purpose of this study is to determine the extent of the development of space dynamics that occur in industrial houses that are influenced by economic factors. The result is that there are 3 types of economic factors there, namely, ordinary economic factors, middle economic factors and high economic factors. Ordinary economic factors affect little space, medium economic factors affect some space (half) in the house while high economic factors affect all patterns of space in the house.
\end{abstract}

\title{
Keywords : economic needs, pia cake industry house, space dynamics
}

\section{PENDAHULUAN}

Pada era globalisasi yang modern ini, semakin banyak jumlah penduduk dan juga tingkat pengangguran serta sedikitnya lapangan pekerjaan yang tersedia. Apalagi tingkat pekerjaan di area perdesaan yang kian sedikit, akibatnya hanya para laki-laki saja sebagai seorang suami yang bekerja dan istrinya tidak bekerja karena menjadi ibu rumah tangga serta mengurus anaknya.

Faktor ekonomi terkait kebutuhan pun masih serba kekurangan dan karena itu pihak Pemerintah Kabupaten Pasuruan merencanakan sebuah terobosan baru yaitu membuat sebuah icon lapangan pekerjaan di suatu area-area pada kota atau tempat tertentu sesuai kelebihan atau yang diproduksi di suatu kota atau tempat tersebut seperti membuka rumah industri yang menjual belikan suatu barang yang di dagangkan. Barang tersebut seperti kue, pakaian batik, celana jeans, pusat oleh-oleh ataupun aksesoris dsb. (Peraturan Bupati Pasuruan, 2017) 
Rumah industri memiliki beberapa kategori yaitu industri kecil, industri sedang (menengah) atau industri besar. Industri rumahan dari skala kecil sampai menengah memiliki peran cukup besar dalam sektor manufaktur di sebuah area dilihat dari berbagai sisi pada jumlah unit usaha dan daya serapnya juga cukup besar terhadap tenaga kerja yang ada (Kuncoro, 2000).

\section{TINJAUAN PUSTAKA}

Ruang merupakan salah satu bagian dari ilmu arsitektur yang memiliki keterikatan dengan sebuah objek, manusia yang merasakan dan melihatnya. Keterikatan tersebut dipengaruhi oleh indera seperti perabaan, penciuman dan pendengaran. Ruang dalam arsitektur terdapat pada teori terkait ruang menurut Rapoport (1997) yang mengemukakan bahwasanya ruang meliputi kegiatan manusia, teritori, area inti, ruang personal dan area terkontrol. Dalam penelitian ini mengambil kajian teori dari Hermanto (2008) yang mengemukakan bahwasanya ruang memiliki beberapa aspek yakni: Bentuk ruang, Ukuran ruang, pembatas ruang, kondisi ruang, dan komponen ruang. Akan tetapi yang dipilih dari aspeknya hanya bentuk ruang dan ukuran ruang saja untuk mengatasi permasalahan yang diteliti. Penjabaran terkait ruang sangatlah luas, dan juga ruang dapat berubah. Perubahan pada ruang bisa dikatakan dengan dinamika ruang.

Dinamika ruang merupakan sebuah manusia untuk hidup dalam kebersamaan dan membentuk suatu ruang sesuai keinginan dan kebutuhan manusia (Smith,1990). Faktor yang disebutkan yaitu karakter individu, karakter masyarakat, dan faktor teknologi.

Faktor ekonomi di dalam sebuah usaha merupakan sebuah kunci penting dalam mengembangkan usaha. Jika ada uang yang lebih, maka wirausahawan bisa untuk melebarkan usahanya agar berkembang lebih besar. Maka dari itu perkembangan industri kue pia yang ada di Kampung Pia Warurejo juga dipengaruhi oleh faktor ekonomi. Faktor ekonomi yang terjadi pada rumah industri kue pia sangat beraneka ragam tergantung dari kualitas dan kuantitas usahanya. Seperti pada Hunian masyarakat pengusaha Bakpia Pathuk di Yogyakarta yang memfokuskan diri untuk memperkenalkan dan membesarkan nama suatu hunian masyarakt disana kepada dunia luar agar nama bakpia pathuk menjadi terkenal dan dapat dikenal oleh semua orang (Listiyani, 2012). Dan juga pada Morfologi Kampung Kalengan kelurahan Bugangan Kota Semarang yang menjelaskan terkait unsur dari morfologi perkembangan sebuah Kampung Kalengan yang memiliki industri kalengan.

Pada penelitian ini bertujuan untuk mengetahui sejauh mana perkembangan dinamika ruang yang terjadi pada rumah industri yang dipengaruhi oleh faktor ekonomi. Permasalahan yang akan dibahas yakni terkait mengetahui sejauh mana perkembangan dinamika ruang yang terjadi pada rumah industri yang dipengaruhi oleh faktor ekonomi. Permasalahan 
tersebut diambil karena ingin melihat sejauh mana perkembangan atau dinamika ruang yang terjadi pada area usaha pada rumah industri kue pia Warurejo Pasuruan.

\section{METODE PENELITIAN}

Penelitian ini merupakan jenis penelitian kualitatif. Metode yang digunakan pada penelitian ini adalah metode fenomenologi. Metode pengumpulan data yakni: Observasi lokasi studi lapangan, wawancara dengan narasumber, dokumentasi atau pengukuran arsitektural. Metode analisis data bersifat deskriptif. Metode ini dipilih karena sangat serasi untuk diaplikasikan pada objek studi di lapangan untuk mengamati pola perubahan rumah industri di Kampung Pia.

Populasi dan sampel yang diteliti ialah pada rumah industri yang telah dipilih berdasarkan analisis triangulasi data (dipilih oleh peneliti). Sampel yang telah dipilih tersebut yaitu pada rumah industri kue pia yang ada di Kampung Pia Warurejo.

Tabel 1. Metode Penelitian

\begin{tabular}{|c|c|c|c|c|}
\hline No & Variabel & Indikator & $\begin{array}{c}\text { Metode } \\
\text { Pengumpulan } \\
\text { Data }\end{array}$ & Analisis Data \\
\hline 1 & Bentuk Ruang & $\begin{array}{l}\text { Dinamika } \\
\text { Ruang }\end{array}$ & $\begin{array}{l}\text { - Observasi } \\
\text { Lapangan }\end{array}$ & $\begin{array}{l}\text { - Analisis Deskriptif } \\
\text { (Antar studi terpilih) }\end{array}$ \\
\hline 2 & Ukuran Ruang & $\begin{array}{c}\text { Rumah } \\
\text { industri kue } \\
\text { pia }\end{array}$ & $\begin{array}{l}\text { - Wawancara } \\
\text { - Dokumentasi } \\
\text { - Pengukuran }\end{array}$ & $\begin{array}{lr}\text { - } & \text { Analisis } \\
\text { (Kajian } & \text { Jomparatif } \\
\text { Terdahulu) } & \text { Jurnal }\end{array}$ \\
\hline
\end{tabular}

Sumber: Analisis Pribadi (2019)

\section{HASIL DAN PEMBAHASAN}

Pada tahapan analisis deskriptif akan mengidentifikasi terkait bentuk ruang dan ukuran ruang pada beberapa permasalahan yang akan diteliti dan pada sampel yang telah terpilih. Kriteria penetapan sampel terfokus pada beberapa kategori sebagai berikut:

a. Rumah industri kue pia, dan

b. Rumah yang memiliki fasilitas mencukupi.

Dari beberapa kategori tersebut dipilih 5 sampel rumah industri kue pia yang memenuhi kriteria di atas. Berikut daftar rumah industri yang telah memenuhi kriteria yakni sebagai berikut:

a. Rumah Bu Astutik [Tipe A (Produksi)],

b. Rumah Bu Lilik [Tipe B (Penjualan)],

c. Rumah pak Maryono [Tipe C (Pengiriman)],

d. Rumah Bu Lastri [Tipe D (Produksi, Penjualan dan Pengiriman)], dan

e. Rumah Bu Srinah [Tipe D (Produksi, Penjualan dan Pengiriman)]. 
Pada rumah industri di atas yang telah memenuhi standar yang mencukupi terkait kriteria yang disebutkan kemudian akan di analisis menggunakan analisis deskriptif dan komparatif terkait bentuk ruang dan ukuran ruang. Analisis deskriptif yang menjelaskan terkait data studi terpilih dan analisis komparatif menjelaskan kajian jurnal terdahulu.

\subsection{Analisis Deskriptif Perubahan Ruang}

Pada rumah industri yang ada di Kampung Pia Warurejo sangat terlihat perkembangannya dari tahun ke tahun. Perubahan terjadi mulai dari sebelum dan sesudah berusaha kue pia. Perubahan tersebut terjadi akibat dari faktor ekonomi dalam berusaha kue pia. Tiap rumah yang mengalami perubahan faktor ekonomi mengalami perubahan yang berbeda-beda tergantung dari tingkat perkembangan perekonomian masing-masing wirausaha kue pia. Berikut tabel yang menjelaskan perubahan yang terjadi akibat dari faktor ekonomi terkait usaha kue pia.

Tabel 2. Rumah Industri Kue Pia sebelum dan sesudah industri kue pia

\begin{tabular}{|c|c|c|c|c|c|c|}
\hline $\begin{array}{l}N \\
0\end{array}$ & $\begin{array}{c}\text { Nama Pemilik } \\
\text { Rumah, Tipe } \\
\text { dan ukuran } \\
\text { luas rumah } \\
\text { industri kue } \\
\text { pia }\end{array}$ & $\begin{array}{l}\text { Fungsi } \\
\text { Rumah }\end{array}$ & $\begin{array}{l}\text { Kategori } \\
\text { Perkemb } \\
\text { angan } \\
\text { Faktor } \\
\text { Ekonomi }\end{array}$ & $\begin{array}{c}\text { Fasilitas Ruang } \\
\text { Sebelum } \\
\text { berwirausaha kue } \\
\text { pia }\end{array}$ & $\begin{array}{c}\text { Perubahan/ } \\
\text { Penambahan Fasilitas } \\
\text { Ruang } \\
\text { Setelah berusaha kue } \\
\text { pia }\end{array}$ & Keterangan \\
\hline 1 & $\begin{array}{l}\text { Bu Astutik } \\
\text { Tipe A } \\
\text { Luas Rumah } \\
243,272 \mathrm{~m} 2\end{array}$ & $\begin{array}{c}\text { Fungsi } \\
\text { Ganda } \\
\text { (Rumah } \\
\text { Tinggal \& } \\
\text { Rumah } \\
\text { Industri) }\end{array}$ & Sedang & $\begin{array}{l}\text { - } \text { Garasi } \\
\text { - Ruang Tamu } \\
\text { - Ruang Tidur } \\
\text { - Ruang Keluarga } \\
\text { - Ruang Setrika } \\
\text { - Ruang Makan } \\
\text { - } \text { Dapur } \\
\text { - KM/WC } \\
\text { - } \text { Gudang }\end{array}$ & $\begin{array}{l}\text { Ruang Tetap: } \\
\text { - Garasi } \\
\text { - Ruang Tamu } \\
\text { - Ruang Tidur } \\
\text { - Ruang Setrika } \\
\text { - Ruang Makan } \\
\text { - Dapur } \\
\text { - KM/WC } \\
\text { - Gudang } \\
\text { Ruang Tambahan: } \\
\text { - Ruang Pengolahan } \\
\quad \text { Kue Pia } \\
\text { Ruang Penambahan } \\
\text { Fungsi Ruang: } \\
\text { - Ruang } \\
\text { Keluarga/Ruang } \\
\text { Pemaketan }\end{array}$ & Tipe A \\
\hline 2 & $\begin{array}{c}\text { Bu Lilik } \\
\text { Tipe B } \\
\text { Luas Rumah } \\
216 \text { m2 } \\
\text { Dan sesudah } \\
\text { terkena faktor } \\
\text { ekonomi } \\
\text { menjadi } 98,49 \\
\text { m2 }\end{array}$ & $\begin{array}{c}\text { Fungsi } \\
\text { Ganda } \\
\text { (Rumah } \\
\text { Tinggal \& } \\
\text { Rumah } \\
\text { Industri) }\end{array}$ & Tinggi & $\begin{array}{l}\text { - Garasi } \\
\text { - Ruang Tamu } \\
\text { - Ruang Tidur } \\
\text { - Ruang Keluarga } \\
\text { - Ruang Makan } \\
\text { - } \text { Dapur } \\
\text { - KM/WC } \\
\text { - Gudang }\end{array}$ & $\begin{array}{l}\text { BANGUNAN BARU } \\
\text { Ruang Tetap: } \\
\text { - Garasi } \\
\text { - } \text { Ruang Tamu } \\
\text { - } \text { Dapur } \\
\text { - KM/WC } \\
\text { - Gudang } \\
\text { Ruang Tambahan: } \\
\text { - Ruang Penjualan Kue } \\
\text { Pia } \\
\text { - Ruang Penyimpanan } \\
\text { Kue Pia }\end{array}$ & Tipe B \\
\hline
\end{tabular}

Jurnal PAWON Jurnal PAWON, Nomor 03 Volume III, Juli-Desember 2019, ISSN 2597-7636 


\begin{tabular}{|c|c|c|c|c|c|c|}
\hline & $\begin{array}{c}\text { Tipe C } \\
\text { Luas Rumah } \\
144 \mathrm{~m} 2\end{array}$ & $\begin{array}{c}\text { Ganda } \\
\text { (Rumah } \\
\text { Tinggal \& } \\
\text { Rumah } \\
\text { Industri) }\end{array}$ & & $\begin{array}{ll}\text { - } & \text { Ruang Tamu } \\
\text { - Ruang Tidur } \\
\text { - Ruang Keluarga } \\
\text { - } \text { Dapur } \\
\text { - KM/WC } \\
\text { - Gudang }\end{array}$ & $\begin{array}{l}\text { - } \text { Garasi } \\
\text { - Ruang Tamu } \\
\text { - Ruang Tidur } \\
\text { - Ruang Keluarga } \\
\text { - } \text { Dapur } \\
\text { - KM/WC } \\
\text { - Gudang } \\
\text { Ruang Tambahan: } \\
\text { - Ruang Penyimpanan } \\
\text { Kue Pia }\end{array}$ & \\
\hline 4 & $\begin{array}{c}\text { Bu Lastri } \\
\text { Tipe D } \\
\text { Luas Rumah } \\
252 \mathrm{~m} 2\end{array}$ & $\begin{array}{l}\text { Fungsi } \\
\text { Ganda } \\
\text { (Rumah } \\
\text { Tinggal \& } \\
\text { Rumah } \\
\text { Industri) }\end{array}$ & Sedang & $\begin{array}{l}\text { - } \text { Garasi } \\
\text { - Ruang Tamu } \\
\text { - Ruang Tidur } \\
\text { - } \text { Ruang Keluarga } \\
\text { - } \text { Dapur } \\
\text { - KM/WC }\end{array}$ & $\begin{array}{l}\text { Ruang Tetap: } \\
\text { - Garasi } \\
\text { - Ruang Tamu } \\
\text { - Ruang Tidur } \\
\text { - Dapur } \\
\text { - KM/WC } \\
\text { Ruang Tambahan: } \\
\text { - Ruang Pengolahan } \\
\text { Kue Pia } \\
\text { - Ruang Penjualan Kue } \\
\quad \text { Pia } \\
\text { Ruang Penambahan } \\
\text { Fungsi Ruang: } \\
\text { Ruang Keluarga/Ruang } \\
\text { Pemaketan }\end{array}$ & Tipe D \\
\hline 5 & $\begin{array}{c}\text { Bu Srinah } \\
\text { Tipe D } \\
\text { Luas Rumah } \\
336 \mathrm{~m} 2\end{array}$ & $\begin{array}{l}\text { Fungsi } \\
\text { Tunggal } \\
\text { (Rumah } \\
\text { Industri) }\end{array}$ & Tinggi & $\begin{array}{ll}\text { - } & \text { Garasi } \\
\text { - } & \text { Ruang Tamu } \\
\text { - } & \text { Ruang Tidur } \\
\text { - } & \text { Ruang Keluarga } \\
\text { - } & \text { Dapur } \\
\text { - KM/WC } \\
\text { - } \text { Gudang }\end{array}$ & $\begin{array}{l}\text { RENOVASI BANGUNAN } \\
\text { Ruang Tetap: } \\
\text { - Garasi } \\
\text { - Ruang Tamu } \\
\text { - Dapur } \\
\text { - KM/WC } \\
\text { - Gudang } \\
\text { Ruang Tambahan: } \\
\text { - Ruang Produksi Kue } \\
\text { Pia } \\
\text { - Ruang Penyimpanan } \\
\text { Kue Pia } \\
\text { - Ruang Penjualan Kue } \\
\text { Pia } \\
\text { - Ruang Pemaketan }\end{array}$ & Tipe D \\
\hline
\end{tabular}

Sumber: Analisis Pribadi (2019)

Dari tabel di atas dijelaskan bahwasanya terdapat perubahan terhadap penambahan ruang ataupun fungsi ruang yang terjadi pada rumah industri kue pia yang ada di Kampung Pia Warurejo sebelum dan sesudah terkena faktor ekonomi. Perubahan terkait penambahan ruang ataupun fungsi menjadi salah satu yang mendominasi pada rumah industri kue pia.

Pada rumah industri kue pia Warurejo terdapat beberapa perkembangan faktor ekonomi yang mempengaruhi terkait perubahan ruangan mulai dari penambahan ruang dan fungsi. Faktor perkembangan ekonomi tersebut terbagi menjadi kategori biasa, sedang dan tinggi. Dalam perkembangan ekonomi sedang, perkembangan akan perubahan ruangan hanya 1-2 ruang saja (sedikit ruang). Pada perkembangan faktor ekonomi sedang, perkembangan akan perubahan ruangan meliputi setengah dari ruangan yang ada di rumah. Serta pada perkembangan faktor ekonomi 
tinggi, perkembangan akan perubahan ruangan meliputi seluruh rumah (bangunan baru).

Pola ruangan yang terjadi pada rumah industri kue pia akan berubah seiring perkembangan atau pengaruh dari faktor ekonomi tiap tahunnya. Perkembangan tersebut digambarkan dalam tabel terkait sampel denah rumah industri kue pia sebelum dan sesudah terkena faktor ekonomi (wirausaha kue pia).

Tabel 3. Denah Rumah Industri Kue Pia sebelum dan sesudah industri kue pia

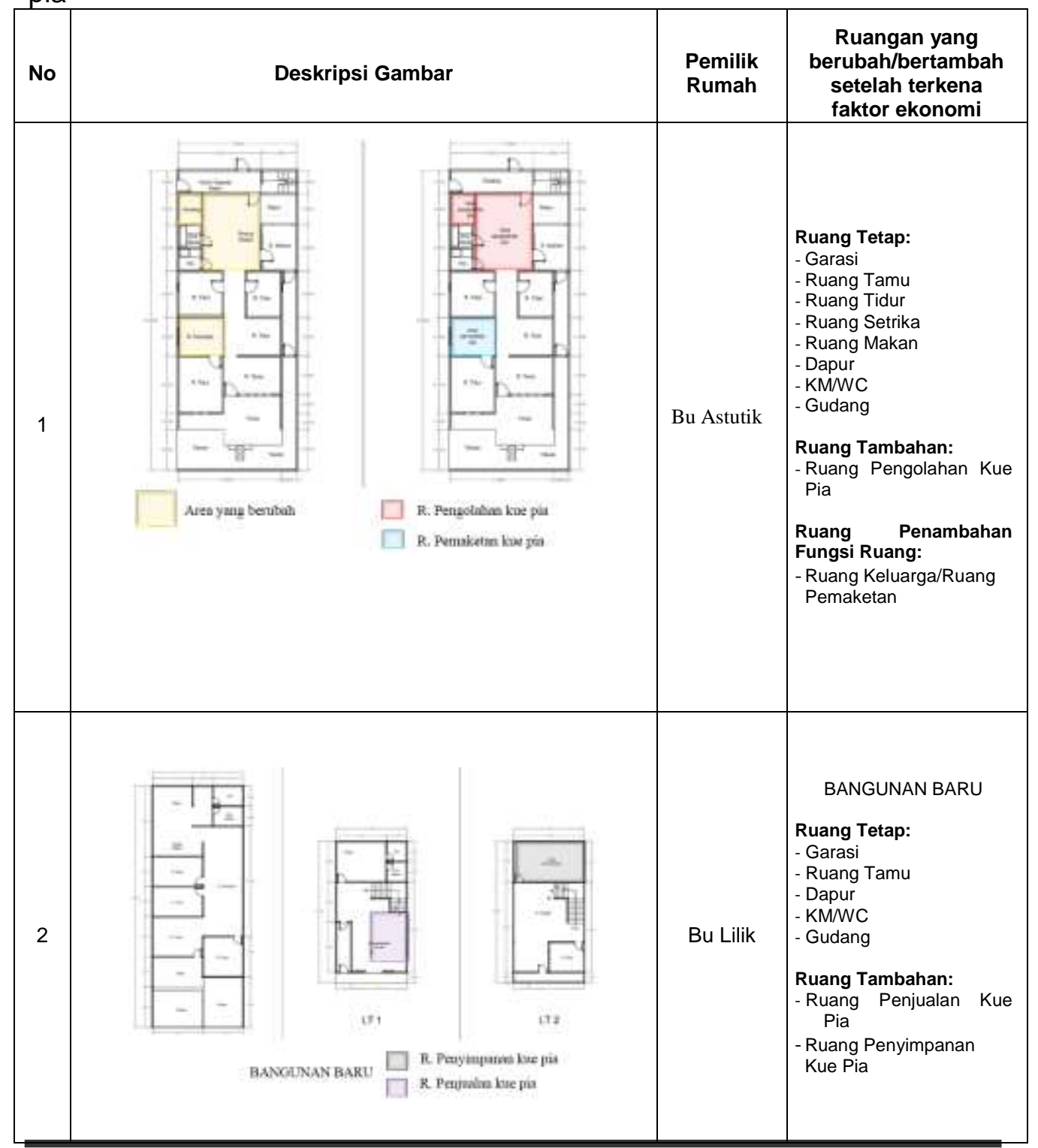

Jurnal PAWON Jurnal PAWON, Nomor 03 Volume III, Juli-Desember 2019, ISSN 2597-7636 


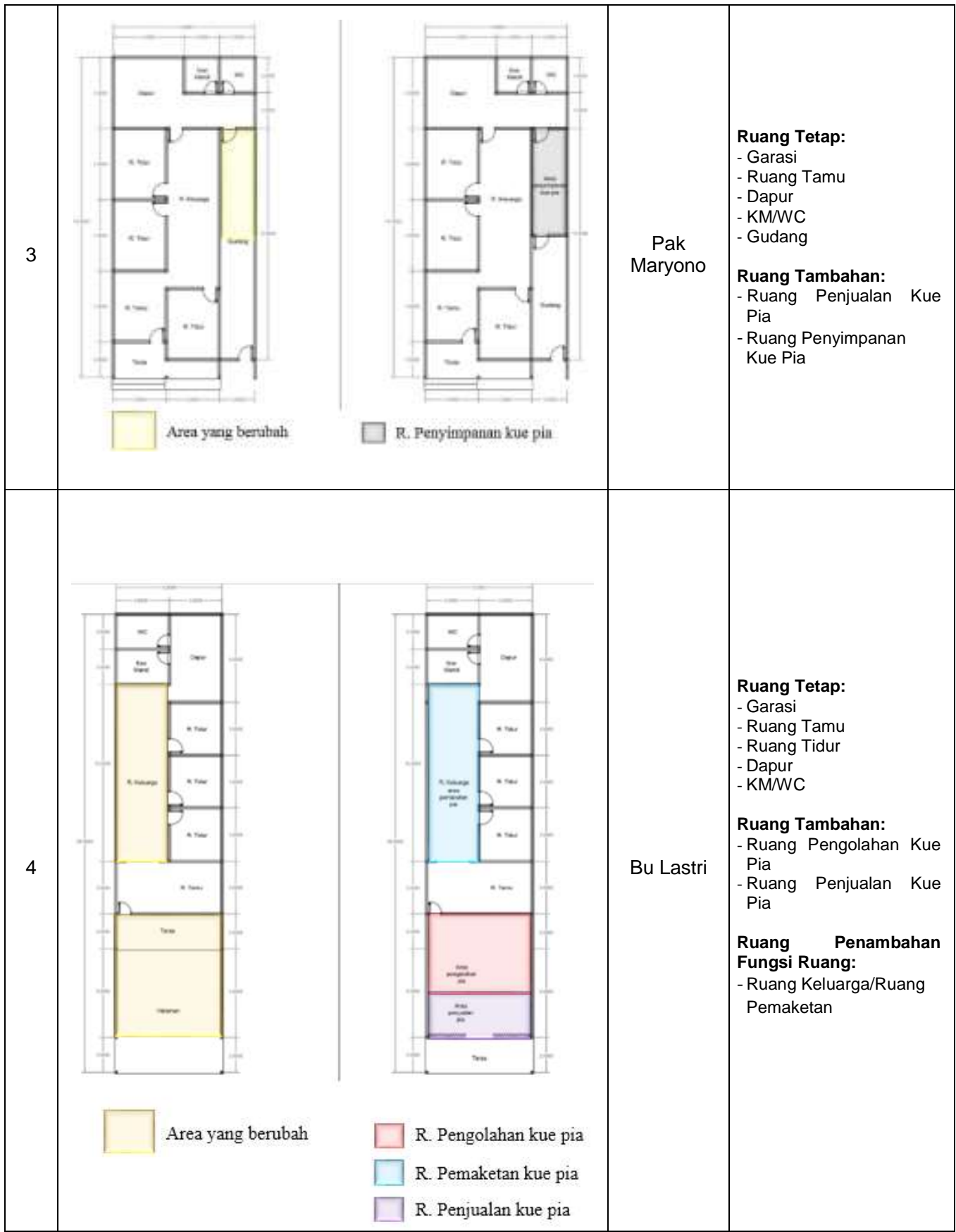




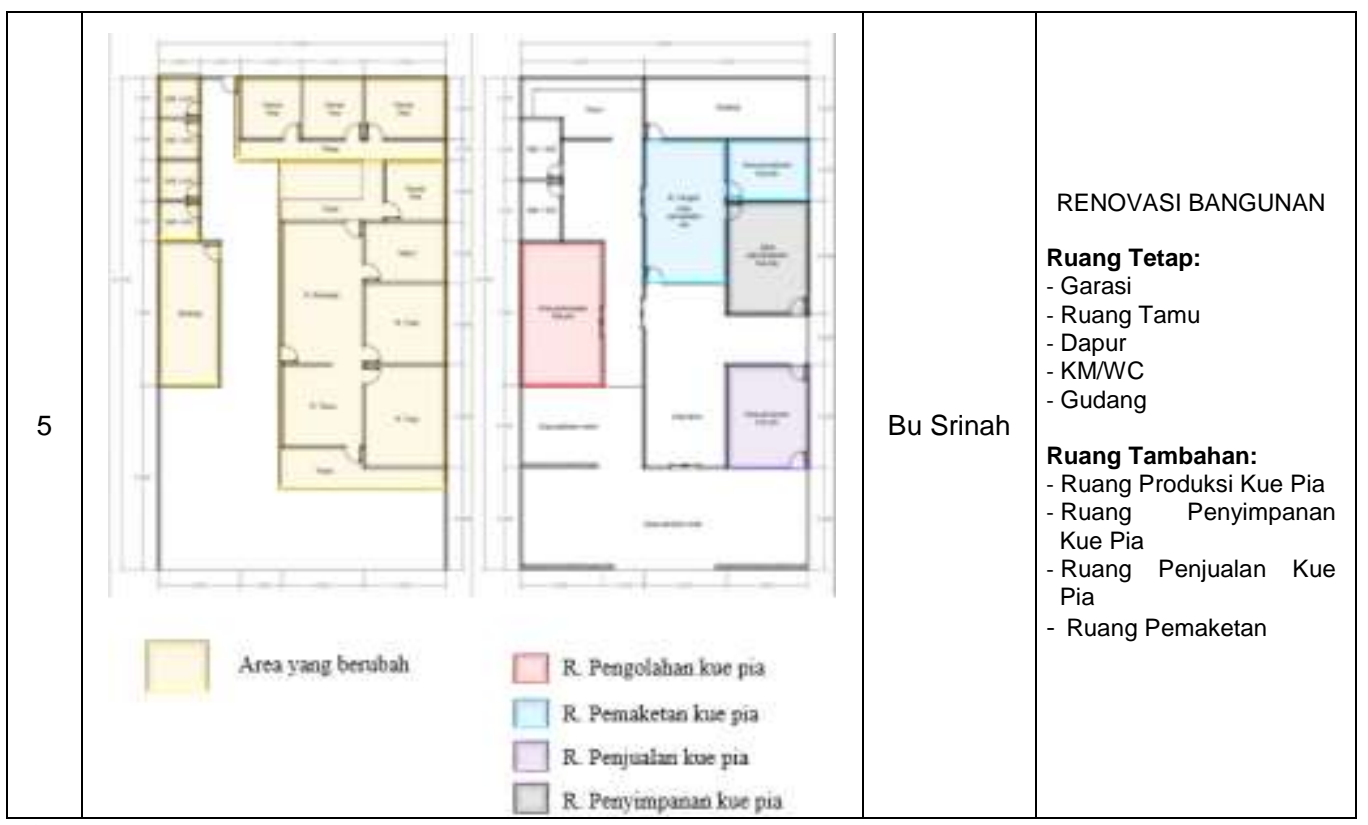

Sumber: Analisis Pribadi (2019)

Dari tabel di atas menjelaskan terkait zona ruang yang berubah akibat dari faktor ekonomi wirausaha kue pia. Perubahan yang menjelaskan sebelum dan sesudah wirausaha kue pia terkait pola ruang ataupun fungsinya.

\subsection{Hasil Penelitian}

Hasil dari penelitian ini menyebutkan bahwasanya ada beberapa faktor ekonomi yang mempengaruhi di Kampung Pia Warurejo yaitu faktor ekonomi biasa (faktor ekonomi yang memiliki jumlah kekayaan dari hasil penjualan yang sedikit), faktor ekonomi sedang (faktor ekonomi yang memiliki jumlah kekayaan dari hasil penjualan yang sedang) dan faktor ekonomi tinggi (faktor ekonomi yang memiliki jumlah kekayaan dari hasil penjualan yang tinggi).

Tingkat dari faktor ekonomi biasa, sedang ataupun tinggi ternyata mempengaruhi tingkat perkembangan perubahan yang terjadi pada area usaha di rumah industri kue pia di Kampung Pia Warurejo. Perubahan skala ekonomi biasa mengubah sedikit ruang yakni satu ruang saja yang dipakai untuk usaha kue pia. Perubahan skala ekonomi menengah mengubah sebagian ruang pada rumah industri kue pia yakni ruang keluarga, teras, dapur, ataupun ruang tidur. Sedangkan perubahan skala ekonomi tinggi mengubah banyak ruang atau bahkan seluruh ruang pada rumah industri kue pia. 


\section{KESIMPULAN}

Pada perubahan yang terjadi di rumah industri kue pia sangat dipengaruhi oleh faktor ekonomi akan kebutuhan yang diinginkan oleh pengusaha kue pia. Perubahan faktor ekonomi tersebut memiliki tingkat yang berbeda-beda mulai dari yang biasa, sedang ataupun tinggi tergantung dari pesatnya omset penjualan pengusaha kue pia. Perubahan tersebut juga memicu akan adanya perubahan atau penambahan ruang yang terjadi pada area usaha di rumah industri kue pia. Temuan yang telah ditemukan adalah semakin besar omset penjualannya (uang), semakin banyak juga perubahan atau penambahan yang terjadi pada area usaha di rumah industri tersebut. Kelebihan dari penelitian ini adalah mengamati dengan cermat setiap perkembangan area usaha pada rumah industri kue pia yang ada di Kampung Pia Warurejo dan kekurangannya adalah tidak adanya bukti data foto terkait pola ruang yang dulu karena saat itu tidak terpikirkan akan meneliti di tempat tersebut.

\section{DAFTAR PUSTAKA}

Fadhilah, 2017. Morfologi Kampung Kalengan kelurahan Bugangan Kota Semarang. Jurnal. Semarang.

Hermanto, 2008. Faktor-faktor yang berpengaruh terhadap perubahan fungsi ruang di serambi pasar induk wonosobo. Tesis. Semarang. Program Pasca Sarjana UNDIP.

Kuncoro, M. (2000 ). The Economics of Industrial Agglomeration and Clustering, 1976 1996:the the Case of Indonesia ( Java ). Unpublished $\mathrm{PhD}$ thesis, the University of Melbourne, Melbourne.

Listiyani, 2012. Hunian Masyarakat pengusaha Bakpia Pathuk di Yogyakarta. Skripsi. Yogyakarta. Universitas Atmajaya Yogyakarta.

Peraturan Bupati Pasuruan Nomor 52. Tahun 2017. Pusat Strategi Dan Layanan Ekonomi Maslahat Dengan Rahmat Tuhan yang Maha Esa. Pasuruan. Peraturan Bupati Pasuruan.

Rapoport, A. (1977). Human Aspect of Urban Form; Toward a Man Environment Approach to Urban Form and Design. Urban and Regional Planning Series, Volume 15.

Smith,D.(1990)."Introduction: the sharing and dividing of geographical space", in Shared Space, Divided Space: Essays on Conflict and Territorial Organization. Eds M Chisholm, D Smith (Unwin Hyman, London) pp 1-21. 